\title{
Up-regulation and redistribution of protein kinase $C-\delta$ in chronically hypoxic heart
}

\author{
Markéta Hlaváčková • Kristýna Kožichová • \\ Jan Neckář • František Kolář · René J. P. Musters • \\ František Novák · Olga Nováková
}

Received: 19 March 2010/Accepted: 27 August 2010/Published online: 19 September 2010

(C) Springer Science+Business Media, LLC. 2010

\begin{abstract}
The adaptation to chronic hypoxia confers long-lasting cardiac protection against acute ischemiareperfusion injury. Protein kinase $\mathrm{C}$ (PKC) appears to play a role in the cardioprotective mechanism but the involvement of individual PKC isoforms remains unclear. The aim of this study was to examine the effects of chronic intermittent hypoxia $(\mathrm{CIH} ; 7,000 \mathrm{~m}, 8 \mathrm{~h} /$ day $)$ and acute administration of PKC- $\delta$ inhibitor (rottlerin, $0.3 \mathrm{mg} / \mathrm{kg}$ ) on the expression and subcellular distribution of PKC- $\delta$ and PKC- $\varepsilon$ in the left ventricular myocardium of adult male Wistar rats by Western blot and quantitative immunofluorescence microscopy. CIH decreased the total level of $\mathrm{PKC}-\varepsilon$ in homogenate without affecting the level of phosphorylated $\mathrm{PKC}-\varepsilon$ (Ser729). In contrast, $\mathrm{CIH}$ up-regulated the total level of PKC- $\delta$ as well as the level of
\end{abstract}

M. Hlaváčková $(\varangle) \cdot$ K. Kožichová · F. Novák · O. Nováková Department of Cell Biology, Faculty of Science, Charles University in Prague, Vinicna 7, 12800 Prague 2,

Czech Republic

e-mail: hlavacko@natur.cuni.cz

M. Hlaváčková · F. Novák

Department of Biochemistry, Faculty of Science,

Charles University in Prague, Prague 2, Czech Republic

J. Neckář · F. Kolár

Institute of Physiology, Academy of Sciences of the Czech

Republic, Prague, Czech Republic

J. Neckář · F. Koláŕ · F. Novák

Centre for Cardiovascular Research, Prague, Czech Republic

R. J. P. Musters

Laboratory for Physiology, Institute for Cardiovascular

Research, Free University of Amsterdam, Amsterdam,

The Netherlands phosphorylated PKC- $\delta$ (Ser643) in homogenate. Rottlerin partially reversed the hypoxia-induced increase in PKC- $\delta$ in the mitochondrial fraction. Immunofluorescent staining of ventricular cryo-sections revealed increased co-localization of $\mathrm{PKC}-\delta$ with mitochondrial and sarcolemmal membranes in $\mathrm{CIH}$ hearts that was suppressed by rottlerin. The formation of nitrotyrosine as a marker of oxidative stress was enhanced in $\mathrm{CIH}$ myocardium, particularly in mitochondria. The expression of total oxidative phosphorylation complexes was slightly decreased by $\mathrm{CIH}$ mainly due to complex II decline. In conclusion, up-regulated PKC- $\delta$ in CIH hearts is mainly localized to mitochondrial and sarcolemmal membranes. The inhibitory effects of rottlerin on PKC- $\delta$ subcellular redistribution and cardioprotection (as shown previously) support the view that this isoform plays a role in the mechanism of CIHinduced ischemic tolerance.

Keywords Chronic hypoxia - Heart - Protein kinase C . Mitochondria $\cdot$ Cardioprotection $\cdot$ PKC delta up-regulation

\section{Introduction}

It has been shown that adaptation of rats to chronic intermittent hypoxia $(\mathrm{CIH})$ protects their hearts against acute ischemia-reperfusion injury. This long-lasting protective phenomenon manifests itself as a reduction in infarct size, limitation of ventricular arrhythmias, and improved recovery of contractile function [1]. Although the cardioprotective effects of $\mathrm{CIH}$ have been known for half a century, and several signaling pathways have been proposed to play a role [1], the detailed mechanism of improved cardiac ischemic tolerance induced by $\mathrm{CIH}$ still remains to be elucidated. 
In analogy to short-lived protection induced by preconditioning, we and others have shown that, for example, protein kinase $\mathrm{C}$ (PKC) [2, 3], phosphatidylinositol 3-kinase/Akt pathway [4], mitochondrial ATP-sensitive potassium (mitoK $\mathrm{ATP}_{\mathrm{AT}}$ ) channels $[5,6]$, and reactive oxygen species (ROS) [7] are involved in the cardioprotective mechanism of $\mathrm{CIH}$, although the precise interactions among these components are unclear. A link among $\mathrm{PKC}$, especially the PKC- $\varepsilon$ isoform, ROS, and mitoK $\mathrm{ATP}_{\text {chan- }}$ nels has been postulated in protection induced by preconditioning [8, 9].

Whereas numerous studies have implicated individual PKC isoforms in cardioprotection induced by preconditioning, data concerning their potential role in the cardioprotective mechanism of $\mathrm{CIH}$ are rather limited and controversial probably due to different animal and hypoxia models [10]. In line with other reports [3, 11], the involvement of $\mathrm{PKC}$ in cardioprotection by chronic hypoxia is supported by the observation that chelerythrine, a general inhibitor of PKC, completely abolished the infarct size-limiting effect of $\mathrm{CIH}$ [2]. Several studies reported enhanced expression and/or redistribution of PKC- $\varepsilon$ to particulate fraction under conditions of chronic hypoxia $[3,11]$ but our recent experiments have shown that redox-sensitive PKC- $\delta$ was up-regulated, and PKC- $\varepsilon$ was either not affected or even moderately down-regulated by $\mathrm{CIH}$ in rat myocardium [2, 7, 12]. Moreover, the infarct size of rats adapted to $\mathrm{CIH}$ exhibited close negative correlation with $\mathrm{PKC}-\delta$ up-regulation in the myocardial particulate fraction [12]. Chronic antioxidant treatment during the hypoxic adaptation period abolished both PKC- $\delta$ upregulation and cardioprotective effect, indicating that these events are critically dependent on increased production of ROS associated with adaptation to $\mathrm{CIH}$ [7]. The involvement of $\mathrm{PKC}-\delta$ in cardioprotection induced by $\mathrm{CIH}$ is further supported by our observation that rottlerin, a PKC- $\delta$ inhibitor, administered before the ischemic period, significantly attenuated the infarct size-limiting effect of $\mathrm{CIH}$ [2]. While these results have brought indirect evidence for the role of $\mathrm{PKC}$, especially $\mathrm{PKC}-\delta$, in the cardioprotective mechanism of $\mathrm{CIH}$, the precise localization of $\mathrm{PKC}$ isoforms in cellular compartments of $\mathrm{CIH}$ myocardium and its relevance to the improved ischemic tolerance remains to be elucidated.

The aim of this study, therefore, was to further investigate the potential involvement of PKC- $\delta$ and PKC- $\varepsilon$ in the cardiac adaptation to $\mathrm{CIH}$. We analyzed the effect of $\mathrm{CIH}$ on the myocardial level of total and phosphorylated forms of PKC- $\delta$ and PKC- $\varepsilon$. Furthermore, we studied effect of rottlerin on myocardial PKC- $\delta$ level and its detailed subcellular distribution after adaptation of rats to $\mathrm{CIH}$ by means of both Western blot analysis and quantitative immunofluorescence microscopy. We used the same experimental protocol under which the inhibitory effect of rottlerin on myocardial ischemic tolerance was observed [2]. Our results suggest that mitochondrial and sarcolemmal membranes are the major targets of PKC- $\delta$ in $\mathrm{CIH}$ adapted hearts and support the involvement of this isoform in the cardioprotective mechanism.

\section{Materials and methods}

Animals

Adult male Wistar rats (250-280 g) were exposed to intermittent high-altitude hypoxia of $7,000 \mathrm{~m}$ in a hypobaric chamber for $8 \mathrm{~h} /$ day, 5 days a week (24-32 exposures). Barometric pressure $\left(P_{\mathrm{B}}\right)$ was lowered stepwise, so that the level equivalent to an altitude of $7,000 \mathrm{~m}\left(P_{\mathrm{B}}=40.9 \mathrm{kPa}\right.$; $P_{\mathrm{O}_{2}}=8.5 \mathrm{kPa}$ ) was reached after 13 exposures [7]. The animals were employed the day after the last hypoxic exposure. The control group of rats was kept for the same period of time at $P_{\mathrm{B}}$ and $P_{\mathrm{O}_{2}}$ equivalent to an altitude of $200 \mathrm{~m}\left(P_{\mathrm{B}}=99 \mathrm{kPa} ; P_{\mathrm{O}_{2}}=20.7 \mathrm{kPa}\right)$. All animals had free access to water and a standard laboratory diet.

Animals were anesthetised with sodium pentobarbital (60 mg/kg ip, Sanofi, Montpellier, France). Rottlerin (Biomol, Plymouth Meeting, PA) was dissolved in DMSO and then diluted with saline and administered into the jugular vein in a dose of $0.3 \mathrm{mg} / \mathrm{kg}$ as a single bolus $(1 \mathrm{ml} /$ $\mathrm{kg}) 15 \mathrm{~min}$ before the excision of the heart; the final dose of DMSO was $6 \mu \mathrm{l} / \mathrm{kg}$ [2]. Controls were given saline $(1 \mathrm{ml} / \mathrm{kg})$ with DMSO. The animals were killed by decapitation, and their hearts were rapidly excised and perfused with Krebs-Henseleit solution containing 2,3butanedione monoxime $(20 \mathrm{mmol} / \mathrm{l})$. Apex and the remaining part of the left ventricular $(\mathrm{LV})$ free wall were dissected, weighed, snap-frozen in liquid nitrogen and stored at liquid nitrogen until use. The study was conducted in accordance with the Guide for the Care and Use of Laboratory Animals published by the US National Institutes of Health (NIH Publication No. 85-23, revised 1996). Experimental protocols were approved by the Animal Care and Use Committee of the Institute of Physiology, Academy of Sciences of the Czech Republic. All the chemical compounds were purchased from Sigma-Aldrich (St. Louis, MO), unless otherwise indicated.

Tissue fractionation and Western blot analysis

Frozen LV myocardium was pulverized at the temperature of liquid nitrogen, followed by Potter-Elvehjem homogenization as described previously [7]. The homogenization buffer for analyses of phosphorylated PKC isoforms contained phosphatases inhibitor sodium orthovanadate 
$(0.1 \mathrm{mM})$ and glycerol-3-phosphate $(10 \mathrm{mM})$ in addition. The homogenate was centrifuged to obtain particulate (all membranes) fraction $(100,000 \times g$ for $60 \mathrm{~min})$ or nuclear-cytoskeletal-enriched (Nucl) $(1,000 \times g$ for $10 \mathrm{~min})$, mitochondria-enriched (Mito) $(8,000 \times g$ for $10 \mathrm{~min})$, microsomal (Micro) $(100,000 \times g$ for $60 \mathrm{~min})$ and cytosolic (Cyto) fractions [2, 7]. The homogenate and pellets of all fractions were re-suspended either in a homogenization buffer (non-extracted fractions; oxidative phosphorylation (OXPHOS) complex analysis) or in a homogenization buffer containing $1 \%$ Triton X-100, held on ice for $60 \mathrm{~min}$ and then centrifuged at $100,000 \times g$ for further $60 \mathrm{~min}$ (TX-extracted fractions; PKC analysis). Triton X-100 was also added to the cytosolic fraction to reach the final concentration of $1 \%$.

Proteins from both TX-extracted and non-extracted fractions were separated by electrophoresis (10 or $15 \%$ SDSPAGE) and transferred to nitrocellulose membranes (Amersham Biosciences, Freiburg, Germany). Equal protein transfer efficiency was verified by staining of membranes with Ponceau S. After blocking with 5\% dry low-fat milk in Tris-buffered saline with Tween 20 (TTBS) for $60 \mathrm{~min}$ at room temperature, membranes were washed and probed (90 min at room temperature) with polyclonal antibodies against PKC- $\delta$ (662-673) and PKC- $\varepsilon$ (728-737) (Research \& Diagnostic Antibodies, Benicia, CA) or (overnight at $4{ }^{\circ} \mathrm{C}$ ) phosphorylated form of $\mathrm{PKC}-\delta$ (p-PKC- $\delta$ ) (Ser643) (Cell Signaling Technology, Beverly, MA) and p-PKC- $\varepsilon$ (Ser729) (Upstate, Billerica, MA). After the membranes were washed with TTBS, they were incubated with the appropriate secondary antibodies conjugated to horseradish peroxidase for $60 \mathrm{~min}$ at room temperature. Bands were visualized by enhanced chemiluminescence on the autoradiographic film (Amersham Biosciences), and ImageQuant software was used for quantification of the relative abundance of PKC isoforms and OXPHOS complexes. In order to ensure the specificity of PKC- $\delta$ and PKC- $\varepsilon$-immunoreactive proteins, prestained molar-mass protein standards, recombinant human PKC- $\delta$ and PKC- $\varepsilon$ standards, rat brain extract, and the blocking immunizing peptides were used. In order to ensure the specificity of OXPHOS complexes-immunoreactive protein, mouse brain mitochondria (MitoSciences, Eugene, OR) were used as a positive control. From each group, one sample was run on the same gel and quantified on the same membrane. Sources for other antisera were as follows: lamin, GAPDH and Na,K-ATPase (Abcam, Cambridge, MA), the kit of monoclonal antibodies against five OXPHOS complexes from rodent mitochondria (MitoSciences).

Quantitative immunofluorescence microscopy

The subcellular redistribution of PKC- $\delta$ induced by $\mathrm{CIH}$, the effect of rottlerin and the effect of $\mathrm{CIH}$ on myocardial nitrotyrosine content were investigated by immunofluorescent staining followed by digital imaging fluorescence microscopy. LV apex cross cryo-sections $(5 \mu \mathrm{m})$ were incubated with a primary antibody raised against rat PKC$\delta$ (662-673) or nitrotyrosine (Molecular Probes, Eugene, OR) and counterstained for nuclei with $4^{\prime}, 6$-diamidino2-phenylindole (DAPI)-containing mounting medium (Vectashield; Vector Laboratories, Burlingame, CA) and either for the sarcolemma with $10 \%$ (vol/vol) wheat-germ agglutinin (WGA; Molecular Probes) or for mitochondria with anti-OXPHOS complexes. They were then incubated with the appropriate Alexa Fluor secondary antibody conjugate (Molecular Probes) and visualized by immunofluorescence microscopy, as described by Bouwman et al. [13]. Sections were qualitatively and quantitatively analyzed with the use of imaging and analysis software (SlideBook $^{\mathrm{TM}}$, version 4.1). Regions of interest from the digital images of the LV cross cryo-sections were selected in a process termed masking, a mask being a binary overlay on a digital image. Masks of segments of cross cryo-sections were created by automatically selecting standardized fluorescence thresholds of the counterstains (either sarcolemmal glycocalyx or mitochondrial OXPHOS complexes). Next, the mean intensities of fluorescence of PKC- $\delta$ or nitrotyrosine within these masks were calculated using SlideBook ${ }^{\mathrm{TM}}$ imaging software. Pearson's correlation factors between channels of multiple regions of interest from at least three digital images per experimental group were derived using the SlightBook ${ }^{\mathrm{TM}}$ co-localization tab.

\section{Statistical analysis}

The results are expressed as means $\pm \mathrm{SE}$. A one-way ANOVA and subsequent Student-Newman-Keuls test were used for comparison of differences in normally distributed variables between groups. Differences were considered as statistically significant when $P<0.05$.

\section{Results}

Purity of subcellular fractions, distribution of OXPHOS complexes

Before PKC analysis in TX-extracted fractions, we attempted to determine the level of non-extracted subcellular fractions purity (Fig. 1). GAPDH as cytosolic and lamin as nuclear markers were distinctly detected in the corresponding fractions. Na,K-ATPase as a sarcolemmal membrane marker was detected in all particulate fractions and OXPHOS complexes as a mitochondria marker were present across all fractions analyzed. As for the effect of 
Fig. 1 Western blot analysis of fraction contamination (a) and mitochondrial OXPHOS complex distribution (b) in individual subcellular fractions. Purity of fractions was analyzed using antisera directed against marker proteins localized predominantly in the cytosol $(G A P D H)$, nucleus (lamin), sarcolemma (Na,K-ATPase), and mitochondria [OXPHOS complexes: NDUFB8 (Complex I), SDHB (Complex II), core protein 2 (Complex III), COX I (Complex IV), F1 $\alpha$ ATP synthase (Complex V)]. Cytosolic (Cyto), nuclearcytoskeletal ( $\mathrm{Nucl})$, mitochondrial (Mito), and microsomal (Micro) nonextracted fractions from left ventricles of normoxic (open columns) and chronically hypoxic (black columns) rats were used. The amount of protein applied to the gel was $5 \mu \mathrm{g}$ for all subcellular fractions. Values are means $\pm \mathrm{SE}$ from three hearts in each group. $* P<0.05$ versus the corresponding normoxic group
A

NORMOXIA

Cyto Nucl Mito Micro

GAPDH

Lamin

$\mathrm{Na}, \mathrm{K}$-ATPase

OXPHOS:

Complex V

Complex III

Complex IV

Complex II

Complex I
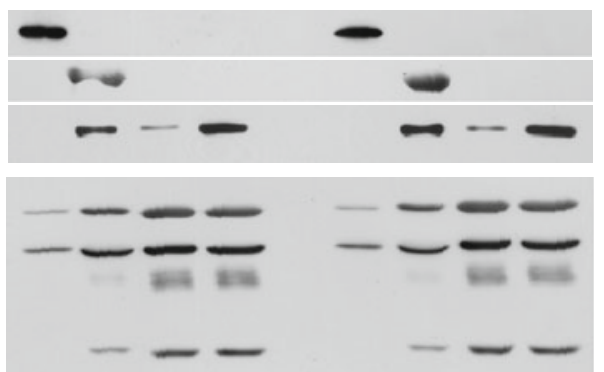

\section{B}
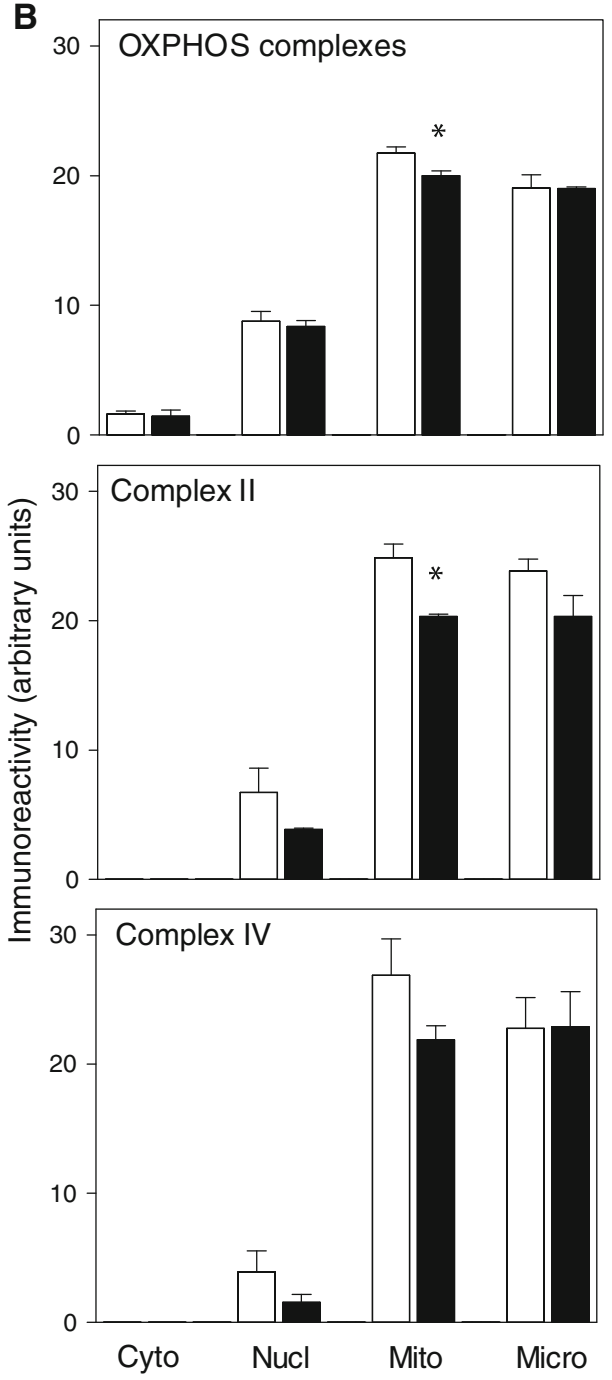

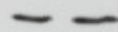

HYPOXIA

Cyto Nucl Mito Micro

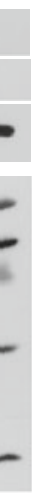


particulate fractions $[7,12]$. The possible explanation for this discrepancy is that different homogenization protocol was used and part of tissue was discarded as a debris in the study where no change of the PKC- $\varepsilon$ level in CIH hearts was detected [2]. It was shown that, in addition to the choice of detergent and its concentration, the way of homogenization and centrifugation protocol could affect myocardial PKC isoforms distribution [14]. In this study, we confirmed that CIH decreased total level of PKC- $\varepsilon$ in LV myocardium. We verified our Western blot results with two different antibodies, the antibody from Sigma and the antibody from Research \& Diagnostic (used also for immunofluorescence microscopy analysis) and obtained comparable results. The adaptation to $\mathrm{CIH}$ decreased the total level of PKC- $\varepsilon$ in homogenate and particulate fraction (by 40 and 37\%, respectively) without affecting the level of p-PKC- $\varepsilon$ (Ser729) (Fig. 2a, b). The ratio of p-PKC- $\varepsilon$ (Ser729) to total PKC- $\varepsilon$ was increased by $\mathrm{CIH}$ in homogenate and cytosolic fraction; the increase in particulate fraction did not reach statistical significance due to higher variability (Fig. 2c). The more detailed analysis of $\mathrm{CIH}$ effect on subcellular fractions revealed the decreased abundance of PKC- $\varepsilon$ in the Mito and Micro fractions (Fig. 3).

\section{Western blot analysis of PKC- $\delta$}

Chronic intermittent hypoxia increased the relative protein content of total PKC- $\delta$ as well as the level of p-PKC- $\delta$ (Ser643) in homogenate by 190 and 204\%, respectively; similar changes were observed in cytosolic and particulate fractions (Fig. 4a, b). The ratio of p-PKC- $\delta$ (Ser643) to total PKC- $\delta$ was not influenced by CIH (Fig. 4c). Rottlerin had no effect on this isoform content in homogenate from either normoxic or hypoxic hearts (Fig. 5a). The detailed analysis showed that $\mathrm{CIH}$ up-regulated $\mathrm{PKC}-\delta$ protein amount in all subcellular fractions with the highest increase in Mito and Micro fractions (Fig. 5b, c). Interestingly, the acute rottlerin treatment significantly decreased the relative PKC- $\delta$ protein content in the Mito fraction in favor of cytosolic and Nucl fractions of $\mathrm{CIH}$-adapted hearts (Fig. 5d).

Immunofluorescence microscopy analysis

Figure 6 shows the PKC- $\delta$ redistribution pattern in response to $\mathrm{CIH}$ and rottlerin in $\mathrm{LV}$ cross cryo-sections. In the normoxic group, a diffuse staining of PKC- $\delta$ can be observed. PKC- $\delta$ was co-localized with nuclei in normoxic as well as in hypoxic hearts. $\mathrm{CIH}$ induced PKC- $\delta$ redistribution and increased PKC- $\delta$ co-localization with the sarcolemma (Fig. 6a, red WGA sarcolemmal glycocalyx counterstain) as well as with the mitochondria (Fig. 6b, red
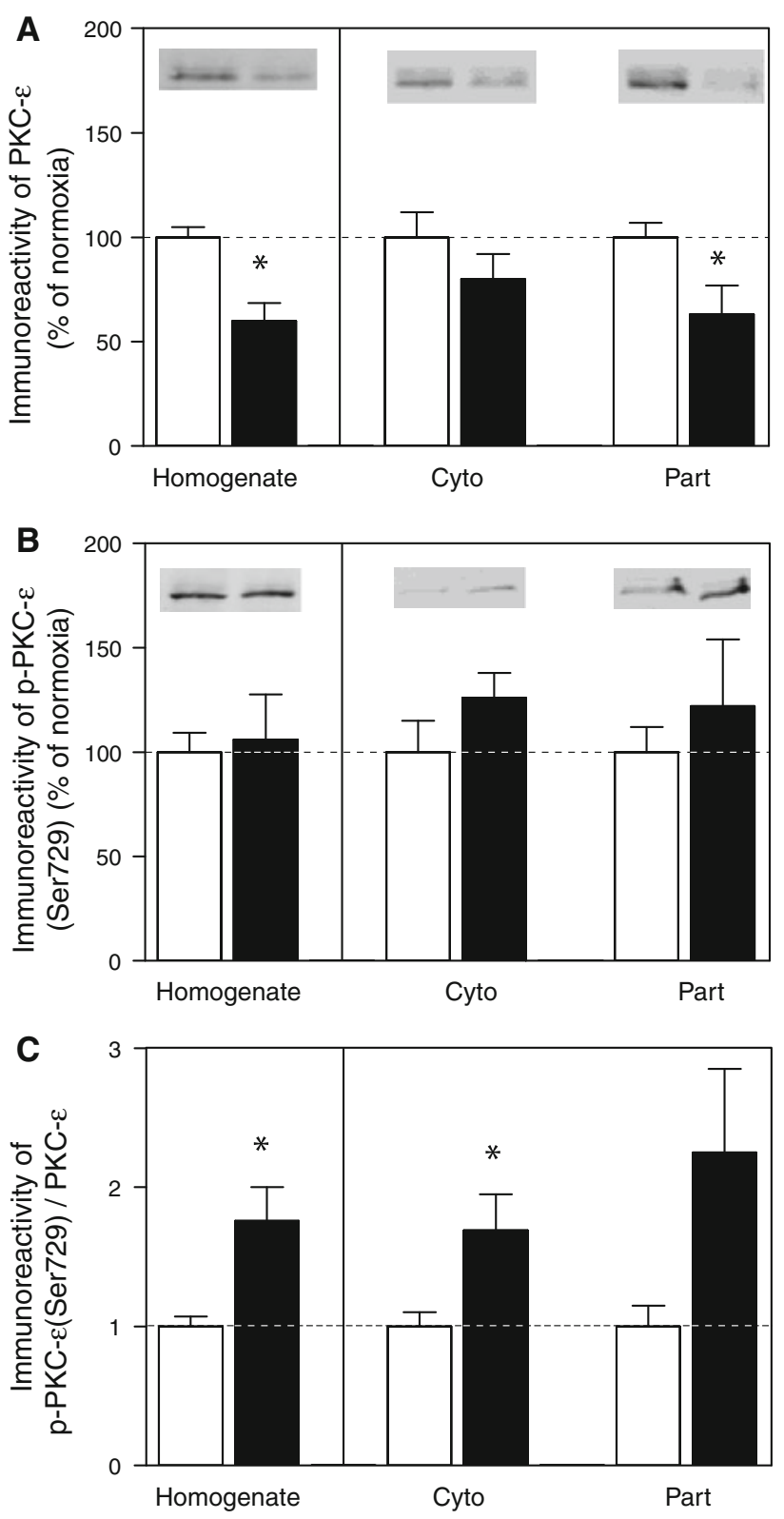

Fig. 2 Effect of $\mathrm{CIH}$ on the level of total PKC- $\varepsilon$ (a), p-PKC- $\varepsilon$ (Ser729) (b), and p-PKC- $\varepsilon$ (Ser729) to total $\mathrm{PKC}-\varepsilon$ ratio (c) in homogenate, cytosolic (Cyto), and total particulate (Part) fractions from left ventricles of normoxic (open columns) and chronically hypoxic (black columns) rats, including representative Western blots. The amount of protein applied to the gel was $10 \mu \mathrm{g}$ (homogenate), $15 \mu \mathrm{g}$ (cytosolic fraction), or $5 \mu \mathrm{g}$ (particulate fraction) for PKC- $\varepsilon$ and $40 \mu \mathrm{g}$ (homogenate), $50 \mu \mathrm{g}$ (cytosolic fraction), or $40 \mu \mathrm{g}$ (particulate fraction) for p-PKC- $\varepsilon$ (Ser729). Values are means $\pm \mathrm{SE}$ from five hearts in each group. $* P<0.05$ versus corresponding normoxic group

OXPHOS counterstain) as indicated by the increase in the yellow-orange color.

Figure 6a, c (left panel) show that the $\mathrm{CIH}$-induced redistribution of PKC- $\delta$ to the sarcolemma (the mean intensity of fluorescence of PKC- $\delta$ in the sarcolemmal 

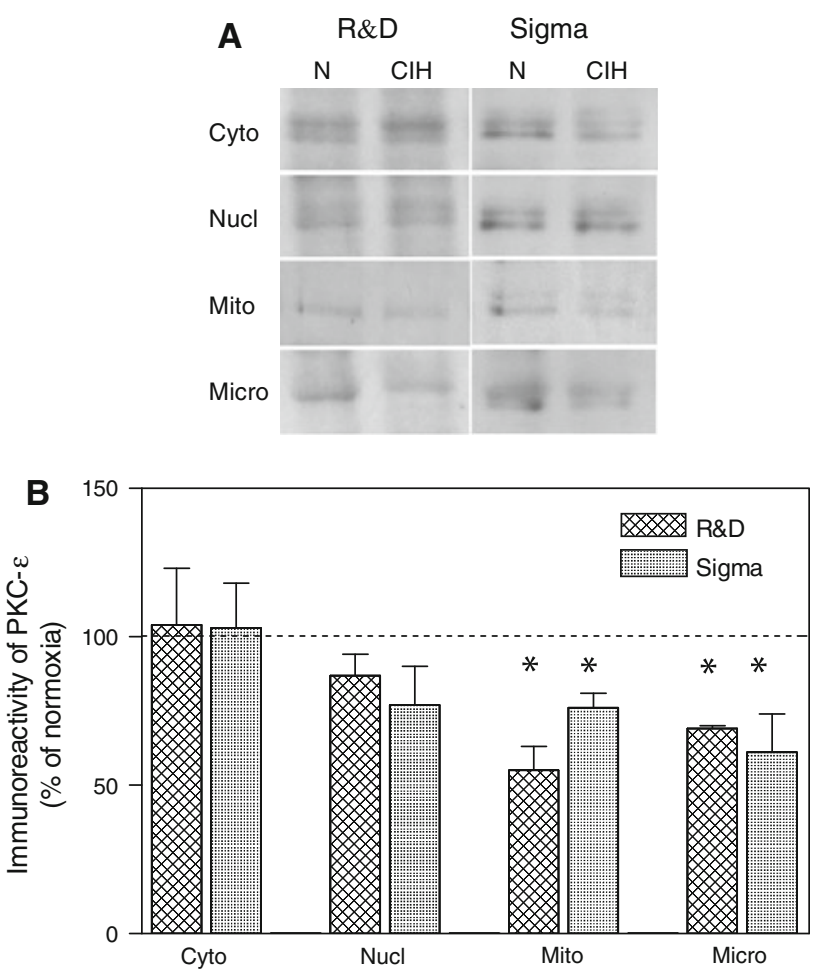

Fig. 3 Representative Western blots (a) showing effect of $\mathrm{CIH}$ on PKC- $\varepsilon$ level in cytosolic (Cyto), nuclear-cytoskeletal ( Nucl), mitochondrial (Mito), and microsomal (Micro) myocardial fractions analyzed by Research \& Diagnostic (R\&D) and Sigma antibodies. Quantified data (b) showing effect of $\mathrm{CIH}$ on PKC- $\varepsilon$ level in subcellular fractions expressed as percentage of normoxic values. The amount of protein applied to the gel was $15 \mu \mathrm{g}(\mathrm{Cyto}), 5 \mu \mathrm{g}(\mathrm{Nucl})$, $10 \mu \mathrm{g}$ (Mito), and $5 \mu \mathrm{g}$ (Micro). Values are means $\pm \mathrm{SE}$ from four hearts in each group. $* P<0.05$ versus corresponding normoxic group

mask was increased by up to $25 \%$ ) was inhibited by rottlerin (the mean intensity of fluorescence of PKC- $\delta$ decreased to the normoxic value). Pearson's correlation factor between the green (PKC- $\delta$ ) and the red channels (sarcolemmal WGA) was calculated to further quantify CIH-induced PKC- $\delta$ co-localization with the sarcolemmal membrane: its mean value in normoxia was $0.31 \pm 0.04$ and significantly increased in $\mathrm{CIH}$ to $0.42 \pm 0.03$. Rottlerin decreased its value in hypoxic tissue down to $0.27 \pm 0.05$. $(P<0.05$; maximum correlation factor is 1$)$.

In Fig. $6 \mathrm{~b}$, the PKC- $\delta$ co-localization with mitochondria (the red OXPHOS counterstain) is shown. In sections of hearts adapted to $\mathrm{CIH}, \mathrm{PKC}-\delta$ was present as a dotted-like distribution pattern with a yellow-orange color (arrows), which indicates the co-localization with the mitochondria. $\mathrm{CIH}$ increased the mean intensity of fluorescence of PKC- $\delta$ in the mitochondrial OXPHOS complexes mask by $19 \%$ (Fig. 6c, right panel), as well as the Pearson's correlation factor between the green (PKC- $\delta$ ) and the red (OXPHOS complexes) channels. Its mean value significantly
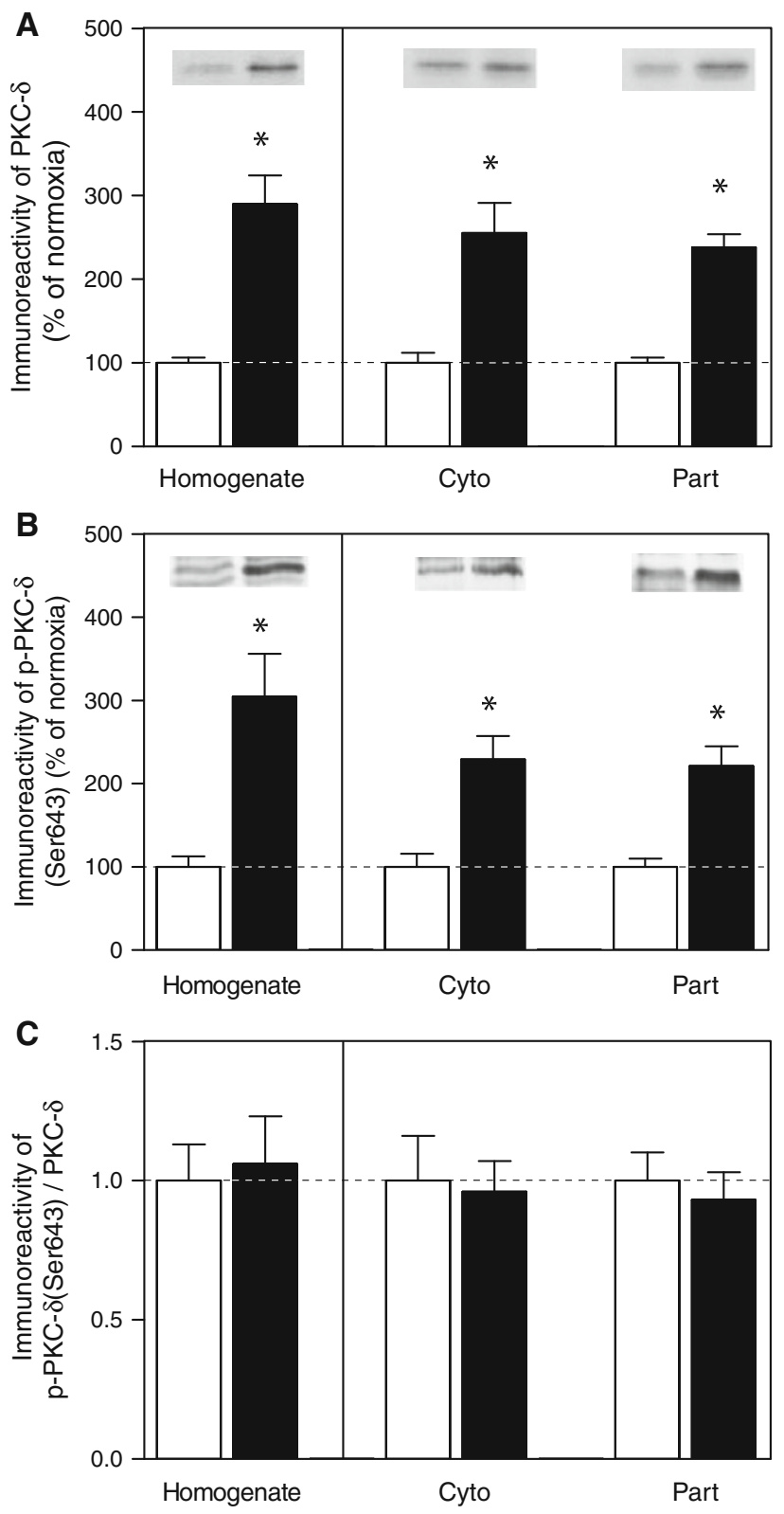

Fig. 4 Effect of $\mathrm{CIH}$ on the level of total PKC- $\delta$ (a), p-PKC- $\delta$ (Ser643) (b), and p-PKC- $\delta$ (Ser643) to total PKC- $\delta$ ratio (c) in homogenate, cytosolic (Cyto), and total particulate (Part) fractions from left ventricles of normoxic (open columns) and chronically hypoxic (black columns) rats, including representative Western blot. The amount of protein applied to the gel was $10 \mu \mathrm{g}$ (homogenate), $15 \mu \mathrm{g}$ (cytosolic fraction), or $5 \mu \mathrm{g}$ (particulate fraction) for $\mathrm{PKC}-\delta$ and $40 \mu \mathrm{g}$ (homogenate), $50 \mu \mathrm{g}$ (cytosolic fraction), or $40 \mu \mathrm{g}$ (particulate fraction) for $\mathrm{p}-\mathrm{PKC}-\delta$ (Ser643). Values are means \pm SE from six hearts in each group. $* P<0.05$ versus corresponding normoxic group

increased from $0.42 \pm 0.04$ in normoxic to $0.58 \pm 0.06$ in hypoxic tissue. Rottlerin reduced PKC- $\delta$ localization in hypoxic mitochondria, decreasing the mean intensity of PKC- $\delta$ fluorescence in the mitochondrial OXPHOS complexes mask to the normoxic control value. Rottlerin did 

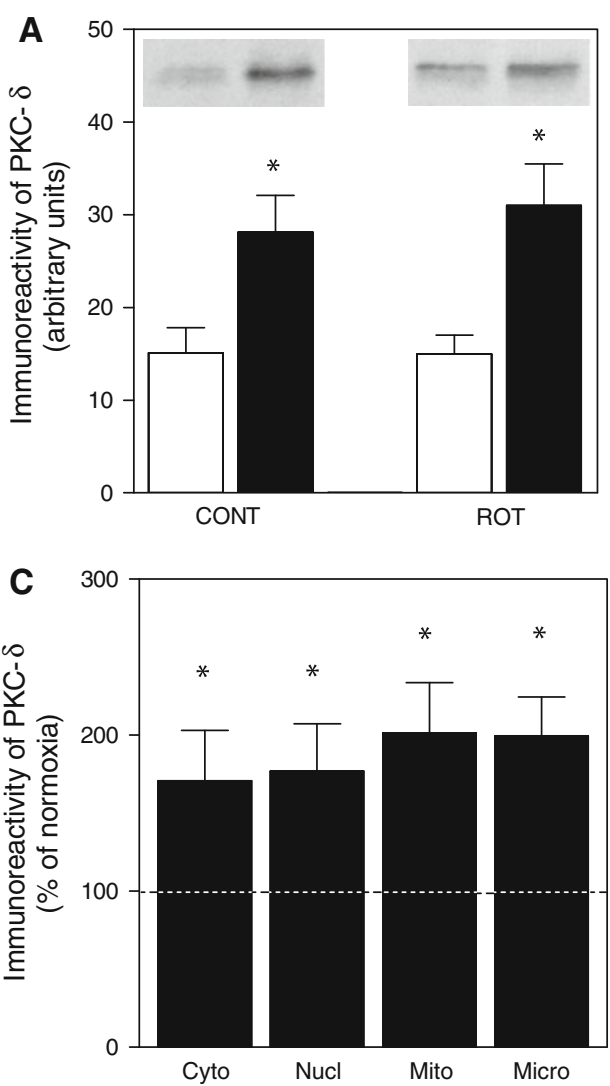

Fig. 5 Effect of $\mathrm{CIH}$ and rottlerin on the level of PKC- $\delta$ in homogenate from left ventricles of normoxic ( $N$; open columns) and chronically hypoxic $(\mathrm{CIH}$; black columns) rats treated by vehicle (CONT) or rottlerin (ROT), including representative Western blots (a). Representative Western blots (b) showing effect of $\mathrm{CIH}$ and rottlerin $(R O T)$ on PKC- $\delta$ abundance in cytosolic (Cyto), nuclearcytoskeletal ( $\mathrm{Nucl}$ ), mitochondrial (Mito), and microsomal (Micro) fractions. Quantified data (c) show effect of $\mathrm{CIH}$ on PKC- $\delta$ level in

not significantly affect the PKC- $\delta$ distribution in normoxic tissue.

Unlike the PKC- $\delta$ staining in normoxic tissue, PKC- $\varepsilon$ displayed a dotted-like distribution pattern. Partial PKC- $\varepsilon$ co-localization with OXPHOS complexes suggests its presence in the mitochondria. Neither $\mathrm{CIH}$ nor rottlerin affected the $\mathrm{PKC}-\varepsilon$ distribution (data not shown).

\section{Effect of $\mathrm{CIH}$ on nitrotyrosine formation}

Figure 7a demonstrates $\mathrm{CIH}$-induced formation of nitrotyrosine. $\mathrm{CIH}$ led to an increase in protein nitrosylation (the overall intensity of fluorescence of nitrotyrosine was increased by $24 \%$ compared to normoxia) and induced protein nitrosylation in mitochondria, nuclei, and sarcolemma (Fig. 7b). The mean Pearson's correlation factor between green (nitrotyrosine) and red channels (OXPHOS complexes) significantly increased from $0.32 \pm 0.02$ in normoxic tissue to $0.40 \pm 0.03$ in hypoxic tissue.
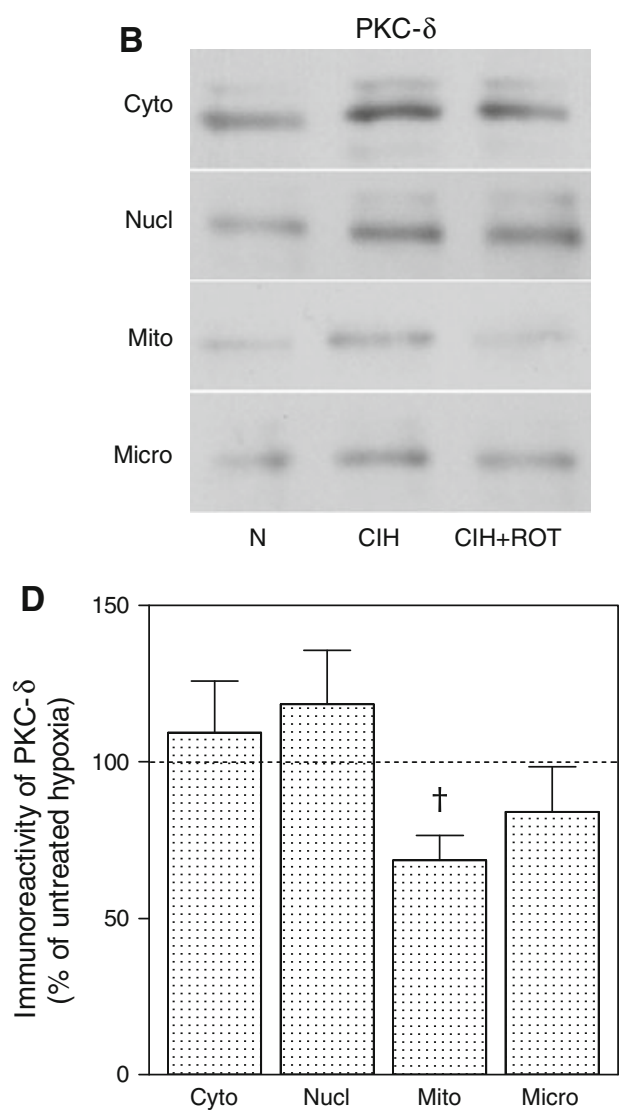

subcellular fractions expressed as percentage of normoxic values. (d) Effect of rottlerin on PKC- $\delta$ level in subcellular fractions from chronically hypoxic rats expressed as percentage of untreated hypoxic values. The amount of protein applied to the gel was $10 \mu \mathrm{g}$ (homogenate), $15 \mu \mathrm{g}$ (Cyto), $5 \mu \mathrm{g}$ (Nucl), $10 \mu \mathrm{g}$ (Mito), and $5 \mu \mathrm{g}$ (Micro). Values are means $\pm \mathrm{SE}$ from five hearts in each group. $* P<0.05$ versus the corresponding normoxic group; ${ }^{\dagger} P<0.05$ versus the untreated hypoxic group

\section{Discussion}

The major novel finding of this study is that the up-regulation of PKC- $\delta$ in LV myocardium of $\mathrm{CIH}$-adapted rats was associated with its enhanced phosphorylation on Ser643 and increased co-localization with markers of mitochondrial and sarcolemmal membranes. Rottlerin, PKC- $\delta$ inhibitor, attenuated $\mathrm{CIH}$-induced effects on the expression and subcellular redistribution of PKC- $\delta$. Concerning $\mathrm{PKC}-\varepsilon$, the adaptation to $\mathrm{CIH}$ decreased its total abundance in myocardium without affecting its distribution and the level of p-PKC- $\varepsilon$ (Ser729). The level of total oxidative phosphorylation complexes was slightly decreased and the formation of nitrotyrosine as a marker of oxidative stress was enhanced in $\mathrm{CIH}$ myocardium, particularly in mitochondria.

The studies dealing with effects of chronic hypoxia on PKC $-\varepsilon$ expression, activity and subcellular distribution are rather controversial, probably due to the diversity of the 

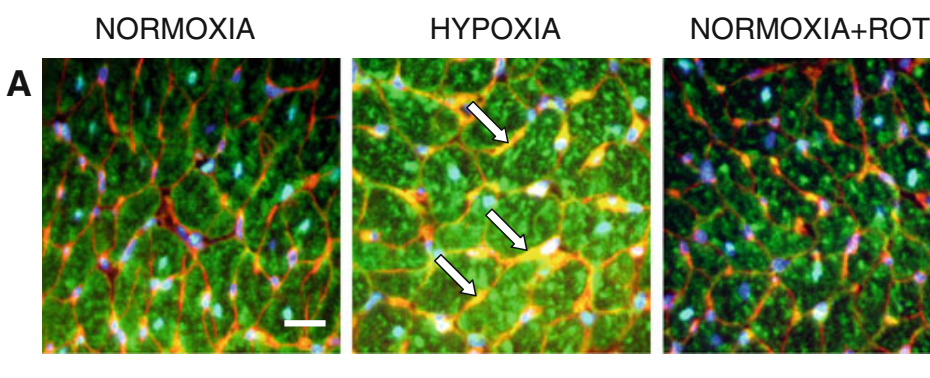

HYPOXIA+ROT

B

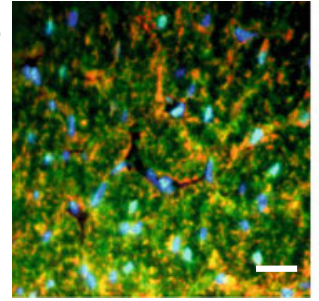

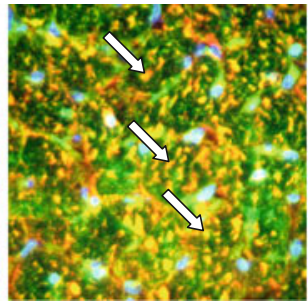
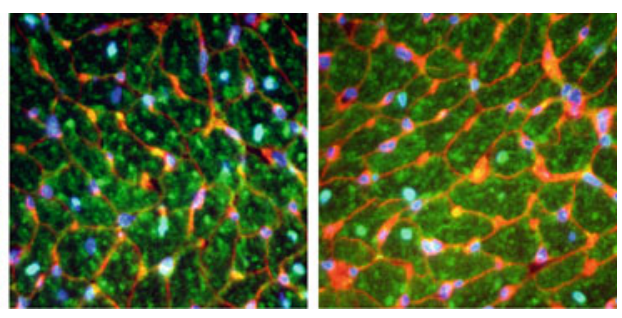

C

Sarcolemmal (WGA) mask
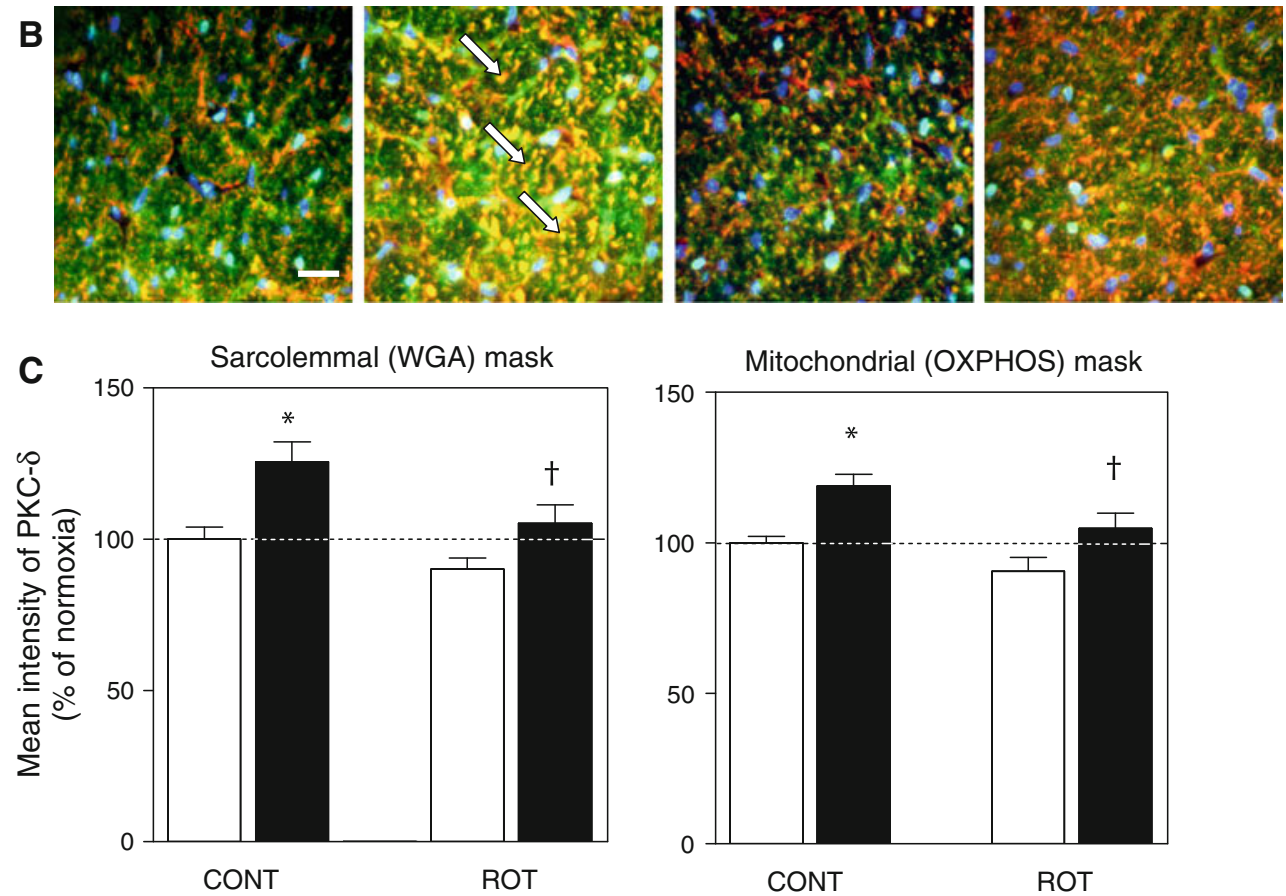

Fig. 6 PKC- $\delta$ distribution and co-localization with sarcolemma (a) and mitochondria (b) in normoxic and chronically hypoxic cross cryo-sections of left ventricles, and the effect of rottlerin (ROT). In all panels, green represents specific PKC- $\delta$ staining and blue indicates the nuclear 4',6-diamidino-2-phenylindole (DAPI) staining. In panels a, red represents the wheat-germ agglutinin (WGA) staining of the sarcolemmal glycocalyx, and in panels b, red represents the OXPHOS complexes. Note the increase in the yellow-orange color in both panels, indicating increased $\mathrm{CIH}$-induced co-localization of $\mathrm{PKC}-\delta$

with sarcolemma and mitochondria (arrows). Bar represents $20 \mu \mathrm{m}$. (c) Quantification of the mean intensity of fluorescence of PKC- $\delta$ in sarcolemma (WGA staining, left panel) and mitochondria (OXPHOS complexes staining, right panel) in cryo-sections from normoxic (open columns) and chronically hypoxic (black columns) rats treated by vehicle (CONT) or rottlerin (ROT) expressed as percentage of normoxic values. Values are means \pm SE from three hearts in each group. ${ }^{*} P<0.05$ versus the normoxic group; ${ }^{\dagger} P<0.05$ versus the untreated hypoxic group (See online version for color pictures)

hypoxic models used $[3,10,15,16]$. In our previous experiments, adaptation to $\mathrm{CIH}$ decreased $\mathrm{PKC}-\varepsilon$ protein amount [7] and similar effect was observed in adult rat myocardium prenatally exposed to hypoxic conditions [17]. It has been reported that $\mathrm{PKC}-\varepsilon$ down-regulation could be caused by PKC- $\delta$-dependent hydrophobic motif phosphorylation of PKC- $\varepsilon$ on Ser729 [18]. Despite the decrease of total PKC- $\varepsilon$ content in this study, the level of phosphorylated form of PKC- $\varepsilon$ (Ser729) was not influenced by $\mathrm{CIH}$, leading to the increase in p-PKC- $\varepsilon$ (Ser729) to total $\mathrm{PKC}-\varepsilon$ ratio. It suggests that the maintenance of phosphorylated (active) $\mathrm{PKC}-\varepsilon$ level is important for myocardial adaptation to $\mathrm{CIH}$. An increased phosphorylation and translocation of PKC- $\varepsilon$ was detected in hearts of

neonatal rabbits under conditions of chronic continuous hypoxia [11]. It is necessary to emphasize that $\mathrm{PKC}-\varepsilon$ is the key component of signal transduction of various forms of preconditioning [19] and cross-regulation of PKC- $\varepsilon$ and PKC- $\delta$ function in cardiomyocytes has been well documented $[18,20]$. The work of Inagaki and Mochly-Rosen [21] showed that the activation of PKC- $\delta$ before ischemic insult led to the activation of PKC- $\varepsilon$ and consequently to cardioprotection. Despite the absence of PKC- $\varepsilon$ up-regulation or subcellular redistribution by $\mathrm{CIH}$ in this study, the fact that the phosphorylated $\mathrm{PKC}-\varepsilon$ level was preserved does not allow to unequivocally exclude the potential involvement of this isoform in the protective mechanism. 

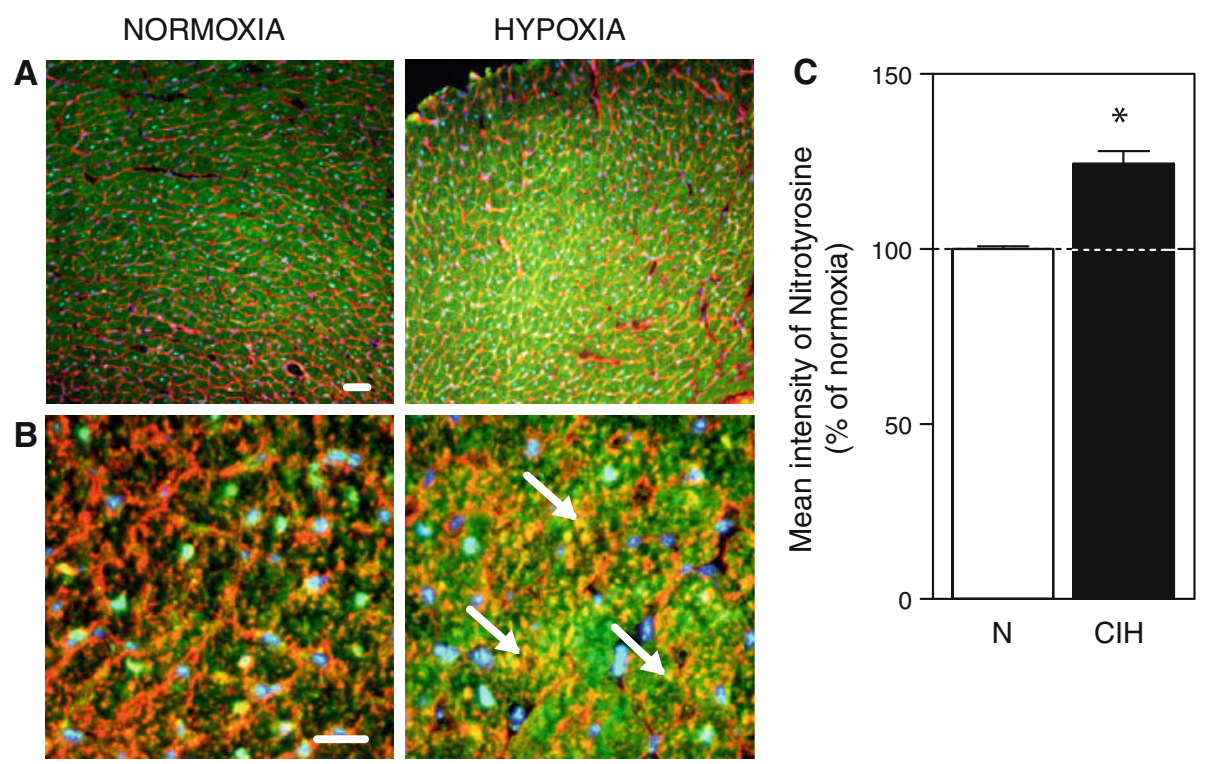

Fig. 7 Nitrotyrosine staining in left ventricular myocardium of normoxic and chronically hypoxic rats. In all panels, green indicates specific nitrotyrosine staining, and blue represents the nuclear $4^{\prime}, 6-$ diamidino-2-phenylindole (DAPI) staining. In panels a, red represents the wheat-germ agglutinin staining of the sarcolemmal glycocalyx, and in panels b, red represents the OXPHOS complexes. Note the increase in mitochondrial protein nitrosylation in hypoxia compared

Concerning PKC- $\delta$, our observation of its significant up-regulation due to adaptation of rats to $\mathrm{CIH}$ corresponds to previous reports using the same $[2,7,12]$ or similar [3] experimental models. Furthermore, we showed that $\mathrm{CIH}$ increased the phosphorylation of PKC- $\delta$ on Ser643 and promoted its increased co-localization with mitochondrial and sarcolemmal membranes. Phosphorylation of PKC- $\delta$ on Ser643 and its translocation to mitochondria was also observed in cardioprotection induced by pharmacological preconditioning [22]. The beneficial role of PKC- $\delta$ associated with its translocation to mitochondria and/or sarcolemma was confirmed in a variety of experiments on ischemic and pharmacological preconditioning [13, 2225]. These protective effects of PKC- $\delta$ were ROS-dependent and related to either mitoK $\mathrm{K}_{\mathrm{ATP}}$ or sarcolemmal $\mathrm{K}_{\mathrm{ATP}}$ $\left(\operatorname{sarcK}_{\mathrm{ATP}}\right)$ channels activation. Similarly to preconditioning, the participation of sarcK $\mathrm{K}_{\mathrm{ATP}}$ and/or mitoK $\mathrm{K}_{\mathrm{ATP}}$ channels in increased ischemic tolerance of chronically hypoxic hearts was reported $[5,6,26]$. In addition, it was shown that PKC- $\delta$ translocation to sarcolemmal membrane is connected with the $\mathrm{Na}^{+} / \mathrm{Ca}^{2+}$ exchanger-dependent cardioprotection [25]. Therefore, it can be speculated that increased co-localization of $\mathrm{PKC}-\delta$ with sarcolemmal membrane could also play a role in CIH-induced myocardial protection.

Konishi et al. [27] reported that PKC- $\delta$ is a redoxsensitive enzyme, and ROS can modulate its function via tyrosine phosphorylation. This study demonstrated to normoxia (arrows). Bar represents $20 \mu \mathrm{m}$. (c) Quantification of the mean intensity of fluorescence of nitrotyrosine in cryo-sections from normoxic $(\mathrm{N}$; open columns) and chronically hypoxic $(\mathrm{CIH}$; black columns) rats expressed as percentage of normoxic values. Values are means \pm SE from three hearts in each group. $* P<0.05$ versus the normoxic group (See online version for color pictures)

increased oxidative/nitrosative stress in $\mathrm{CIH}$ hearts by enhanced nitrotyrosine formation. Tyrosine nitration leads to the generation of antigenic epitopes on proteins, the changes in catalytic activity of enzymes [28] and could also influence their translocation, as shown, e.g., for $\mathrm{PKC}-\varepsilon$ [29]. Concerning the role of PKC- $\delta$ and ROS in $\mathrm{CIH}-$ induced cardioprotection, our recent study showed that chronic antioxidant treatment during the adaptation period eliminated both PKC- $\delta$ up-regulation and infarct size reduction, suggesting ROS-dependence of both events [7].

The observation that PKC- $\delta$ up-regulation in $\mathrm{CIH}$ hearts was co-localized with mitochondria prompted us to analyze OXPHOS complexes in detail. OXPHOS complexes were distributed across all subcellular fractions, though with different abundance. The OXPHOS distribution in fractions is in line with the study of Guo et al. [30], who measured immunoreactivity and activity of cytochrome $c$ oxidase in the rat heart using similar homogenization and fractionation protocol. Mito and Micro fractions exhibited the highest OXPHOS enrichment. The later fraction is considered to contain mitochondrial fragments in addition to other membranes, such as sarcolemma and sarcoplasmic reticulum. The relatively high abundance of OXPHOS complexes in the Nucl fraction, which contains mainly broken cell debris, nuclei, cytoskeletal, and myofibrillar proteins, probably reflects the presence of interfibrillar mitochondria [31]. Our observation of the decrease in OXPHOS complexes is in agreement with our previous 
study where $\mathrm{CIH}$ reduced the concentration of myocardial cardiolipin [32], a mitochondrial inner membrane lipid marker. Less severe chronic continuous hypoxia $(5,000 \mathrm{~m}$, 21 days) caused a global decrease in all OXPHOS complex activities [33]. Furthermore, decreased LV mitochondrial respiratory capacity in rats adapted to chronic continuous hypoxia $\left(11 \% \mathrm{O}_{2}, 4\right.$ weeks) was observed [34]. On the other hand, an increase in the activity of OXPHOS complexes I and III was found in the hearts of rats adapted to long-lasting high-altitude hypoxia (4,340 m, 84 days) [35]. As for the relation between PKC- $\varepsilon$ and OXPHOS complexes, an interaction of PKC- $\varepsilon$ with cytochrome $c$ oxidase subunit IV associated with improved cytochrome $c$ oxidase activity was documented in preconditioned myocardium $[30,36]$. In agreement with these results, we observed a tendency to CIH-induced attenuation of OXPHOS complex IV and the down-regulation of PKC- $\varepsilon$ in fractions with the highest OXPHOS enrichment. Concerning PKC- $\delta$, the d-subunit of $\mathrm{F}_{1} \mathrm{~F}_{0}$ ATPase was shown as its possible target in mitochondria. Enhanced PKC- $\delta$ expression in cardiac mitochondria and its co-immunoprecipitation with the d-subunit of $F_{1} F_{0}$ ATPase have suggested that this putative interaction mediates inhibition of $\mathrm{F}_{1} \mathrm{~F}_{0}$ ATPase or ATP synthase activities during prolonged hypoxia [37]. In addition, Mayr et al. [38] postulated the necessity of PKC- $\delta$ presence for a protective shift from aerobic to anaerobic metabolism induced by ischemic preconditioning. In accordance, it has been shown that PKC- $\delta$ inhibits the pyruvate dehydrogenase complex [39], thereby likely contributing to the shift from aerobic to anaerobic metabolism observed in $\mathrm{CIH}$-adapted hearts [40]. Furthermore, a link among PKC- $\delta$, autophagy, and cardioprotection was documented. Autophagy and cardioprotection were abolished in rat hearts perfused with recombinant inhibitor of autophagy Tat-Atg5 (K130R) [41]. Autophagy may be the way for removing damaged mitochondria under $\mathrm{CIH}$ conditions, when the decrease in OXPHOS complexes occurs.

The function of PKC- $\delta$ in myocardial ischemia-reperfusion injury and its precise involvement in the mechanism of protection is still a matter of debate. One of the reasons of this ambiguity could be the greatest flexibility of PKC- $\delta$ among all PKC isoforms to affect various cellular functions because its subcellular localization is finely regulated by phosphorylation at multiple serine/threonine and tyrosine residues [42]. The timing and subcellular location of PKC$\delta$ activation appears to be a critical factor in the manifestation of either protective or detrimental functions of this isoform in the heart. Whereas the activation of PKC- $\delta$ during reperfusion leads to a stimulation of pro-apoptotic pathways [43] and exacerbation of myocardial injury [44], the activation of the enzyme well before an ischemic insult is cardioprotective [21]. The advanced up-regulation of PKC- $\delta$ in cellular membranes, as an important prerequisite of its protective action, is well fulfilled under our $\mathrm{CIH}$ conditions. Mayr et al. [45] evidenced PKC- $\delta$ involvement in the preconditioning-induced cardioprotection using PKC- $\delta$-null mice. In another study, they also showed that inhibition of PKC- $\varepsilon$ resulted in compensatory phosphorylation and mitochondrial translocation of $\mathrm{PKC}-\delta$, providing a possible explanation for the synergy of PKC- $\delta$ and PKC- $\varepsilon$ in cardioprotection [46]. This phenomenon can play a role under $\mathrm{CIH}$ conditions where PKC- $\delta$ was up-regulated and redistributed to mitochondria while $\mathrm{PKC}-\varepsilon$ was either not affected or even moderately down-regulated in rat myocardium $[2,7,12]$.

In this study, we observed that rottlerin, a PKC- $\delta$ inhibitor, reversed $\mathrm{CIH}$-induced $\mathrm{PKC}-\delta$ redistribution to the Mito fraction without affecting the total protein amount of PKC- $\delta$ in homogenate. It was shown that acute rottlerin administration before preconditioning inhibited PKC- $\delta$ translocation to mitochondria [47] and nuclei [22]. Moreover, it was documented that ATP-competitive inhibitors, where rottlerin belongs to [48], affect redistribution of DAG-sensitive PKC isoforms (e.g., PKC- $\delta$ ) by altering their DAG sensitivity perhaps by disrupting their closed conformation [49]. Although PKC- $\delta$ is inhibited by rottlerin more effectively than other PKC isoforms [48], it is necessary to consider possible nonspecific effects of this compound [50]. Nevertheless, our immunofluorescence microscopy analysis revealed that rottlerin treatment partially reversed CIH-induced PKC- $\delta$ co-localization with the sarcolemma and mitochondria. These results are in line with the inhibitory effect of rottlerin on the improved ischemic tolerance of $\mathrm{CIH}$ adapted rat hearts [2] and support the view that $\mathrm{PKC}-\delta$ plays a role in the cardioprotective mechanism of $\mathrm{CIH}$. However, we are aware that these results need to be verified by using more selective PKC inhibitors and searching for possible PKC- $\delta$ targets in sarcolemmal and mitochondrial membranes. The involvement of other PKC isoforms in cardioprotective effect of $\mathrm{CIH}$ cannot be excluded in view of the complete inhibition of cardioprotection by chelerythrine [2].

We conclude that the increase of PKC- $\delta$ expression in $\mathrm{CIH}$-adapted rat hearts is localized mainly to mitochondrial and sarcolemmal membranes. $\mathrm{CIH}$-induced PKC- $\delta$ subcellular redistribution was reversed by acute treatment with its inhibitor, rottlerin. Our results are in line with the view that PKC- $\delta$ mediates the cardioprotective effect of chronic hypoxia, probably via its mitochondrial and sarcolemmal target(s).

Acknowledgments This study was supported by the Grant Agency of the Czech Republic (305/07/0875), the Grant Agency of the Charles University in Prague (97908), and the Ministry of Education, Youth and Sports of the Czech Republic (0021620858). 


\section{References}

1. Kolar F, Ostadal B (2004) Molecular mechanisms of cardiac protection by adaptation to chronic hypoxia. Physiol Res 53: S3-S13

2. Neckar J, Markova I, Novak F, Novakova O, Szarszoi O, Ostadal B, Kolar F (2005) Increased expression and altered subcellular distribution of PKC-delta in chronically hypoxic rat myocardium: involvement in cardioprotection. Am J Physiol Heart Circ Physiol 288:H1566-H1572. doi:10.1152/ajpheart.00586.2004

3. Ding HL, Zhu HF, Dong JW, Zhu WZ, Zhou ZN (2004) Intermittent hypoxia protects the rat heart against ischemia/reperfusion injury by activating protein kinase C. Life Sci 75:25872603. doi:10.1016/j.lfs.2004.07.005

4. Ravingerova T, Matejikova J, Neckar J, Andelova E, Kolar F (2007) Differential role of PI3K/Akt pathway in the infarct size limitation and antiarrhythmic protection in the rat heart. Mol Cell Biochem 297:111-120. doi:10.1007/s11010-006-9335-z

5. Neckar J, Szarszoi O, Koten L, Papousek F, Ostadal B, Grover GJ, Kolar F (2002) Effects of mitochondrial K(ATP) modulators on cardioprotection induced by chronic high altitude hypoxia in rats. Cardiovasc Res 55:567-575. doi:10.1016/S0008-6363(02) 00456-X

6. Zhu HF, Dong JW, Zhu WZ, Ding HL, Zhou ZN (2003) ATPdependent potassium channels involved in the cardiac protection induced by intermittent hypoxia against ischemia/reperfusion injury. Life Sci 73:1275-1287. doi:10.1016/S0024-3205(03) 00429-6

7. Kolar F, Jezkova J, Balkova P, Breh J, Neckar J, Novak F, Novakova $\mathrm{O}$, Tomasova $\mathrm{H}$, Srbova M, Ostadal B, Wilhelm J, Herget J (2007) Role of oxidative stress in PKC-delta up-regulation and cardioprotection induced by chronic intermittent hypoxia. Am J Physiol Heart Circ Physiol 292:H224-H230. doi:10.1152/ ajpheart.00689.2006

8. Zhang HY, McPherson BC, Liu H, Baman TS, Rock P, Yao Z (2002) $\mathrm{H}_{2} \mathrm{O}_{2}$ opens mitochondrial $\mathrm{K}$ (ATP) channels and inhibits GABA receptors via protein kinase $\mathrm{C}$-epsilon in cardiomyocytes. Am J Physiol Heart Circ Physiol 282:H1395-H1403. doi: 10.1152/ajpheart.00683.2001

9. Pain T, Yang XM, Critz SD, Yue Y, Nakano A, Liu GS, Heusch G, Cohen MV, Downey JM (2000) Opening of mitochondrial $\mathrm{K}$ (ATP) channels triggers the preconditioned state by generating free radicals. Circ Res 87:460-466

10. Kolar F, Novak F, Neckar J, Novakova O, Hlavackova M, Ostadal B, Musters RJP (2009) Role of protein kinases in chronic intermittent hypoxia-induced cardioprotection. In: Xi L, Serebrovskaya TV (eds) Intermittent hypoxia. Nova Science Publishers, Hauppauge, pp 175-191

11. Rafiee P, Shi Y, Kong X, Pritchard KA Jr, Tweddell JS, Litwin SB, Mussatto K, Jaquiss RD, Su J, Baker JE (2002) Activation of protein kinases in chronically hypoxic infant human and rabbit hearts: role in cardioprotection. Circulation 106:239-245. doi: 10.1161/01.CIR.0000022018.68965.6D

12. Hlavackova M, Neckar J, Jezkova J, Balkova P, Stankova B, Novakova O, Kolar F, Novak F (2007) Dietary polyunsaturated fatty acids alter myocardial protein kinase $\mathrm{C}$ expression and affect cardioprotection induced by chronic hypoxia. Exp Biol Med 232:823-832

13. Bouwman RA, Musters RJP, van Beek-Harmsen BJ, de Lange JJ, Boer C (2004) Reactive oxygen species precede protein kinase C-delta activation independent of adenosine triphosphate-sensitive mitochondrial channel opening in sevoflurane-induced cardioprotection. Anesthesiology 100:506-514

14. Hunter JC, Korzick DH (2005) Protein kinase C distribution and translocation in rat myocardium: methodological considerations.
J Pharmacol Toxicol Methods 51:129-138. doi:10.1016/j.vascn. 2004.10.003

15. Morel OE, Buvry A, Le Corvoisier P, Tual L, Favret F, Leon-Velarde F, Crozatier B, Richalet JP (2003) Effects of nifedipine-induced pulmonary vasodilatation on cardiac receptors and protein kinase $\mathrm{C}$ isoforms in the chronically hypoxic rat. Pflugers Arch 446:356-364. doi:10.1007/s00424-003-1034-y

16. Uenoyama M, Ogata S, Nakanishi K, Kanazawa F, Hiroi S, Tominaga S, Seo A, Matsui T, Kawai T, Suzuki S (2010) Protein kinase $\mathrm{C}$ mRNA and protein expressions in hypobaric hypoxiainduced cardiac hypertrophy in rats. Acta Physiol 198:431-440. doi:10.1111/j.1748-1716.2009.02064.x

17. Li G, Bae S, Zhang L (2004) Effect of prenatal hypoxia on heat stress-mediated cardioprotection in adult rat heart. Am J Physiol Heart Circ Physiol 286:H1712-H1719. doi:10.1152/ajpheart. 00898.2003

18. Rybin VO, Sabri A, Short J, Braz JC, Molkentin JD, Steinberg SF (2003) Cross-regulation of novel protein kinase C (PKC) isoform function in cardiomyocytes. Role of PKC epsilon in activation loop phosphorylations and PKC delta in hydrophobic motif phosphorylations. J Biol Chem 278:14555-14564. doi:10.1074/ jbc.M212644200

19. Budas GR, Churchill EN, Mochly-Rosen D (2007) Cardioprotective mechanisms of PKC isozyme-selective activators and inhibitors in the treatment of ischemia-reperfusion injury. Pharmacol Res 55:523-536. doi:10.1016/j.phrs.2007.04.005

20. Rybin VO, Guo J, Gertsberg Z, Elouardighi H, Steinberg SF (2007) Protein kinase Cepsilon (PKCepsilon) and Src control PKCdelta activation loop phosphorylation in cardiomyocytes. J Biol Chem 282:23631-23638. doi:10.1074/jbc.M7016 76200

21. Inagaki K, Mochly-Rosen D (2005) DeltaPKC-mediated activation of epsilonPKC in ethanol-induced cardiac protection from ischemia. J Mol Cell Cardiol 39:203-211. doi:10.1016/j.yjmcc. 2005.05.014

22. Uecker M, da Silva R, Grampp T, Pasch T, Schaub MC, Zaugg M (2003) Translocation of protein kinase $C$ isoforms to subcellular targets in ischemic and anesthetic preconditioning. Anesthesiology $99: 138-147$

23. Hirotani S, Sadoshima J (2005) Preconditioning effects of PKCdelta. J Mol Cell Cardiol 39:719-721. doi:10.1016/j.yjmcc. 2005.07.001

24. Marinovic J, Bosnjak ZJ, Stadnicka A (2005) Preconditioning by isoflurane induces lasting sensitization of the cardiac sarcolemmal adenosine triphosphate-sensitive potassium channel by a protein kinase C-delta-mediated mechanism. Anesthesiology 103:540-547

25. Bouwman RA, Salic K, Padding FG, Eringa EC, van BeekHarmsen BJ, Matsuda T, Baba A, Musters RJ, Paulus WJ, de Lange JJ, Boer C (2006) Cardioprotection via activation of protein kinase $\mathrm{C}$-delta depends on modulation of the reverse mode of the $\mathrm{Na}^{+} / \mathrm{Ca}^{2+}$ exchanger. Circulation 114:I226-I232. doi:10.1161/CIRCULATIONAHA.105.000570

26. Kong X, Tweddell JS, Gross GJ, Baker JE (2001) Sarcolemmal and mitochondrial $\mathrm{K}_{\mathrm{ATP}}$ channels mediate cardioprotection in chronically hypoxic hearts. J Mol Cell Cardiol 33:1041-1045. doi:10.1006/jmcc.2001.1362

27. Konishi H, Yamauchi E, Taniguchi H, Yamamoto T, Matsuzaki H, Takemura Y, Ohmae K, Kikkawa U, Nishizuka Y (2001) Phosphorylation sites of protein kinase $\mathrm{C}$ delta in $\mathrm{H} 2 \mathrm{O} 2$-treated cells and its activation by tyrosine kinase in vitro. Proc Natl Acad Sci USA 98:6587-6592. doi:10.1073/pnas.111158798

28. Pacher P, Beckman JS, Liaudet L (2007) Nitric oxide and peroxynitrite in health and disease. Physiol Rev 87:315-424. doi: 10.1152/physrev.00029.2006 
29. Balafanova Z, Bolli R, Zhang J, Zheng Y, Pass JM, Bhatnagar A, Tang XL, Wang O, Cardwell E, Ping P (2002) Nitric oxide (NO) induces nitration of protein kinase Cepsilon (PKCepsilon), facilitating PKCepsilon translocation via enhanced PKCepsilonRACK2 interactions: a novel mechanism of NO-triggered activation of PKCepsilon. J Biol Chem 277:15021-15027. doi: 10.1074/jbc.M112451200

30. Guo D, Nguyen T, Ogbi M, Tawfik H, Ma G, Yu Q, Caldwell RW, Johnson JA (2007) Protein kinase C-epsilon coimmunoprecipitates with cytochrome oxidase subunit IV and is associated with improved cytochrome-c oxidase activity and cardioprotection. Am J Physiol Heart Circ Physiol 293:H2219-H2230. doi: 10.1152/ajpheart.01306.2006

31. Palmer JW, Tandler B, Hoppel CL (1977) Biochemical properties of subsarcolemmal and interfibrillar mitochondria isolated from rat cardiac muscle. J Biol Chem 252:8731-8739

32. Jezkova J, Novakova O, Kolar F, Tvrzicka E, Neckar J, Novak F (2002) Chronic hypoxia alters fatty acid composition of phospholipids in right and left ventricular myocardium. Mol Cell Biochem 232:49-56. doi:10.1023/A:1014889115509

33. Nouette-Gaulain K, Malgat M, Rocher C, Savineau JP, Marthan R, Mazat JP, Sztark F (2005) Time course of differential mitochondrial energy metabolism adaptation to chronic hypoxia in right and left ventricles. Cardiovasc Res 66:132-140. doi: 10.1016/j.cardiores.2004.12.023

34. Zungu M, Young ME, Stanley WC, Essop MF (2008) Expression of mitochondrial regulatory genes parallels respiratory capacity and contractile function in a rat model of hypoxia-induced right ventricular hypertrophy. Mol Cell Biochem 318:175-181. doi: 10.1007/s11010-008-9867-5

35. Zaobornyj T, Valdez LB, Iglesias DE, Gasco M, Gonzales GF, Boveris A (2009) Mitochondrial nitric oxide metabolism during rat heart adaptation to high altitude: effect of sildenafil, L-NAME, and L-arginine treatments. Am J Physiol Heart Circ Physiol 296:H1741-H1747. doi:10.1152/ajpheart.00422.2008

36. Ogbi M, Johnson JA (2006) Protein kinase Cepsilon interacts with cytochrome $\mathrm{c}$ oxidase subunit IV and enhances cytochrome $c$ oxidase activity in neonatal cardiac myocyte preconditioning. Biochem J 393:191-199. doi:10.1042/BJ20050757

37. Nguyen T, Ogbi M, Johnson JA (2008) Delta protein kinase C interacts with the $\mathrm{d}$ subunit of the F1F0 ATPase in neonatal cardiac myocytes exposed to hypoxia or phorbol ester. Implications for F1F0 ATPase regulation. J Biol Chem 283:2983129840. doi:10.1074/jbc.M801642200

38. Mayr M, Chung YL, Mayr U, McGregor E, Troy H, Baier G, Leitges M, Dunn MJ, Griffiths JR, Xu Q (2004) Loss of PKCdelta alters cardiac metabolism. Am J Physiol Heart Circ Physiol 287:H937-H945. doi:10.1152/ajpheart.00877.2003

39. Churchill EN, Murriel CL, Chen CH, Mochly-Rosen D, Szweda LI (2005) Reperfusion-induced translocation of deltaPKC to cardiac mitochondria prevents pyruvate dehydrogenase reactivation. Circ Res 97:78-85. doi:10.1161/01.RES.0000173896. 32522.6ev1

40. Bass A, Ostadal B, Prochazka J, Pelouch V, Samanek M, Stejskalova M (1989) Intermittent high altitude-induced changes in energy metabolism in the rat myocardium and their reversibility. Physiol Bohemoslov 38:155-161

41. Huang C, Liu W, Perry CN, Yitzhaki S, Lee Y, Yuan H, Tsukada YT, Hamacher-Brady A, Mentzer RM Jr, Gottlieb RA (2010) Autophagy and protein kinase $\mathrm{C}$ are required for cardioprotection by sulfaphenazole. Am J Physiol Heart Circ Physiol 298:H570 H579. doi:10.1152/ajpheart.00716.2009

42. Steinberg SF (2004) Distinctive activation mechanisms and functions for protein kinase Cdelta. Biochem J 384:449-459. doi: 10.1042/BJ20040704

43. Murriel CL, Churchill E, Inagaki K, Szweda LI, Mochly-Rosen D (2004) Protein kinase Cdelta activation induces apoptosis in response to cardiac ischemia and reperfusion damage: a mechanism involving $\mathrm{BAD}$ and the mitochondria. $\mathrm{J}$ Biol Chem 279:47985-47991. doi:10.1074/jbc.M405071200

44. Inagaki K, Chen L, Ikeno F, Lee FH, Imahashi K, Bouley DM, Rezaee M, Yock PG, Murphy E, Mochly-Rosen D (2003) Inhibition of delta-protein kinase $\mathrm{C}$ protects against reperfusion injury of the ischemic heart in vivo. Circulation 108:2304-2307. doi: 10.1161/01.CIR.0000101682.24138.36

45. Mayr M, Metzler B, Chung YL, McGregor E, Mayr U, Troy H, Hu Y, Leitges M, Pachinger O, Griffiths JR, Dunn MJ, Xu Q (2004) Ischemic preconditioning exaggerates cardiac damage in PKC-delta null mice. Am J Physiol Heart Circ Physiol 287:H946-H956. doi:10.1152/ajpheart.00878.2003

46. Mayr M, Liem D, Zhang J, Li X, Avliyakulov NK, Yang JI, Young G, Vondriska TM, Ladroue C, Madhu B, Griffiths JR, Gomes A, Xu Q, Ping P (2009) Proteomic and metabolomic analysis of cardioprotection: interplay between protein kinase $\mathrm{C}$ epsilon and delta in regulating glucose metabolism of murine hearts. J Mol Cell Cardiol 46:268-277. doi:10.1016/j.yjmcc. 2008.10.008

47. Fryer RM, Wang Y, Hsu AK, Gross GJ (2001) Essential activation of PKC-delta in opioid-initiated cardioprotection. Am J Physiol Heart Circ Physiol 280:H1346-H1353

48. Gschwendt M, Müller HJ, Kielbassa K, Zang R, Kittstein W, Rincke G, Marks F (1994) Rottlerin, a novel protein kinase inhibitor. Biochem Biophys Res Commun 199:93-98. doi: 10.1006/bbrc.1994.1199

49. Takahashi H, Namiki H (2007) Mechanism of membrane redistribution of protein kinase $\mathrm{C}$ by its ATP-competitive inhibitors. Biochem J 405:331-340. doi:10.1042/BJ20070299

50. Soltoff SP (2007) Rottlerin: an inappropriate and ineffective inhibitor of PKCdelta. Trends Pharmacol Sci 28:453-458. doi: 10.1016/j.tips.2007.07.003 